\title{
REFLECTIONS The state and future of research at the University of Cape Town's Faculty of Health Sciences
}

\author{
Gregory D Hussey, Anthony Hawkridge
}

The nature of research has continued to change considerably over the last century. Our Faculty's challenge has been to keep abreast of those changes to remain at the cutting edge, while contributing meaningfully to the scientific literature which informs clinical and public health practice in South Africa and beyond. The Faculty must possess an agreed-on research strategy that is dynamic and responsive. Over the years our Faculty has 'grown' such a strategy document. This article, summarising its main thrusts, is offered because we feel that while it applies specifically to the University of Cape Town, the issues raised surely apply to all similar faculties in our country and on the continent, to varying degrees.

S Afr Med J 2012;102(6):412-414

\section{Our history}

The Faculty of Health Sciences (FHS) of the University of Cape Town (UCT) has a long and proud tradition of research, built on the shoulders of many individuals. Jack Brock, Professor in Medicine from 1938 until 1970 and one of South Africa's most distinguished nutrition scientists and medical educators, ${ }^{1}$ authored the Faculty's, and probably the country's, first published research strategy document in $1939 .{ }^{2}$ When he started at UCT, research was in its infancy and under his direction research in the Faculty flourished. $\mathrm{He}$ highlighted the importance of exposing undergraduate and postgraduate students to research methods in order to enhance their critical thinking. Brock was an early proponent of the establishment of registrar training. He emphasised the need for basic scientists to collaborate with clinicians and stressed the importance of external organisations and in particular government funding research. His work significantly focused on linking clinical problems to social and economic inequities. He was instrumental in setting up the first formal research unit at our Faculty, initially called the 'Research Unit in Social Medicine' and later the 'Clinical Nutrition Research Unit'.

\section{Our current situation}

UCT was ranked first in Africa by the Times Higher Education World University Rankings 2011 - 2012. ${ }^{3}$ The FHS is strong in research, producing more accredited journal output units than equivalent South African faculties and accounting for about a third of all UCT publications. ${ }^{4}$ The Faculty hosts 8 of UCT's 33 National Research Foundation (NRF) chairs, and 9 of its 30 NRF A-rated scientists. Three of them (Professors Mizrahi, Noakes and Bateman) head world-leading institutes: the Institute of Infectious Disease and Molecular Medicine, the Sports Science Institute and the Lung Institute, respectively.

Gregory Hussey is Professor at the Institute of Infectious Disease and Molecular Medicine and Department of Clinical Laboratory Sciences, University of Cape Town (UCT). Anthony Hawkridge is a consultant in the Research Office, Faculty of Health Sciences, UCT.
The FHS has an impressive track record of innovation and translation. The South African Tuberculosis Vaccine Initiative (SATVI), the South African AIDS Vaccine Initiative (SAAVI), the Desmond Tutu HIV Centre (DTHC), the Clinical Infectious Diseases Research Initiative and the Lung and Infection Unit (some of whose work is published in this issue) are world famous for their translational clinical work, most of which is conducted at field sites within the Western Cape.

The FHS is a major training centre for postdoctoral research fellows and postgraduate students, helping to develop the next generation of biomedical researchers through targeted programmes. Overall the Faculty trains over 1000 postgraduate students per year, including approximately 400 clinical registrars.

\section{The context}

We aspire to being ranked among the top 50 health science faculties in the world. To achieve this, account must be taken of SA's changing position in an increasingly complex and competitive global environment. Historically, SA might have had a comparative advantage. However, China, India and Brazil are major new players in health research. Research in their institutions enjoys substantial governmental support, giving them a distinct advantage over most SA institutions, in an era in which funders are increasingly looking to engage in partnerships, rather than being sole funders. While our government has supported health science research at UCT, the level of funding is insufficient to encourage the type of research enterprise required to improve our global standing.

Our Faculty is committed to responding to the major health challenges of Africa and the world. Our mission statement commits us to being evidence-based in research, to engage constructively with the healthcare needs of all Africans through research, and to undertake research relevant to the needs of our country, our continent and the world. Our Faculty's values include striving for high ethical and professional standards, informed by evidence, commitment to the principles of respect for human rights and human dignity, and quality care, health equity and social justice in all our research.

\section{The need}

We are committed to 'planning for and building the future'. This encompasses issues of resource allocation, and the utilisation of scarce resources. We wish to move beyond doing 'silo research' to much more collaboration, internally and externally, and thereby build partnerships and involve more stakeholders in our planning efforts. 
Projects supported, and themes adopted, by the FHS must also be aligned with the Afropolitan initiative of UCT's Vice-Chancellor. ${ }^{5}$

We operate in a complex environment, particularly regarding our relationship with the Department of Health. The Health Professions Council (HPCSA) and the Colleges of Medicine now require all registrars to complete a research project before they can register as specialists, thus also impacting the Faculty.

There is a need for better priority-setting with regard to what research is conducted and for a process which is fairer, more transparent and more aligned with the needs of the population served by the FHS. The influence of the external donor environment must also be acknowledged. As we seek research funding, there is increasing pressure upon the FHS from agencies such as the World Health Organization (WHO) and other major role-players, to focus on translating research findings into practice, and to improve research management and co-ordination. While these agencies cannot dictate research agenda, they are nevertheless influential in that they control the resources for which we apply.

\section{Our future}

\section{Improving research infrastructure}

The Faculty has good research infrastructure, including dedicated physical research space, scarce research equipment, research laboratories and support systems. However, this infrastructure should be improved and augmented.

\section{Clinical research facility}

A major infrastructural deficit at UCT is the lack of a dedicated clinical research facility. Most clinical research in the Faculty is conducted opportunistically, within existing available spaces, i.e. hospital wards, outpatient departments, operating theatres or at field sites.

The Faculty is in the process of setting up a Core Facility for Clinical Research, Innovation, Translation and Training (C-CRITT), with units located at the Groote Schuur and Red Cross War Memorial Children's Hospital campuses. C-CRITT will promote multidisciplinary clinical research projects, encourage collaborations between basic, public health and clinical scientists, train physicians and other health professionals in clinical research, and foster development, and maintenance, of a critical mass of expert clinical investigators.

C-CRITT will also provide structured training to postgraduate students enrolled in the MMed, MD and $\mathrm{PhD}$ programmes. Training will include induction courses to improve trainees' background understanding of relevant scientific and medical disciplines and, at the same time, improve their research and management skills.

\section{Building the future scientific leadership}

The academic clinical research workforce in South Africa has declined in numbers since the early 1990s. The combined burden of clinical teaching and training, health service provision, and research falls on a shrinking and ageing pool of academics in health science faculties. Consequently, there is limited capacity to increase the production of healthcare professionals, train and inspire a new generation of researchers and continue to cope with the increasing demands of clinical service imposed by the epidemics of communicable and noncommunicable diseases.

At UCT the critical shortage of academic practitioners is demonstrated by the difficulties encountered in the filling of key academic posts. The critical shortage of academic clinicians is being addressed by introducing programmes of research degrees, run in parallel with the professional training programmes. We have introduced intercalated
MB ChB/BSc Honours, $\mathrm{MB} \mathrm{ChB} / \mathrm{MPH}, \mathrm{MB} \mathrm{ChB} / \mathrm{PhD}$ programmes; and a coursework-based $\mathrm{PhD}$ programme for postgraduates in all the professions (nursing, occupational therapy, speech and language pathology, physiotherapy and medicine). These target students in the top $5-10 \%$ of each graduating class are most able, talented and motivated, and most likely to become leaders in their fields. We aim to produce at least $100 \mathrm{PhD}$-trained clinician scientists over the next 10 years at UCT and hope to recruit students also from historically black institutions in SA and from Africa.

The Faculty has also developed several other programmes to support postgraduates and to develop our future research leaders:

The Academic PhD Programme. The FHS traditionally trains two groups of $\mathrm{PhD}$ students - the larger comes from basic science disciplines and the smaller from clinical, public health and rehabilitation disciplines. A strategic objective for the next 10 years is to increase the number of clinician scientists, without neglecting our obligations to the basic scientists. Our model for developing the next generation of academics is to ensure that they are adequately exposed to the research environment (at least $70 \%$ of their time), spend a small proportion of time in teaching and administration, and are exposed to elements of social responsiveness within the divisions where they undertake their training. In 2010 - 2011 the Carnegie Corporation funded $18 \mathrm{PhD}$ and 6 postdoctoral fellows through a grant to UCT for the 'Developing the Next Generation of Academics' programme. We are actively seeking additional funding to expand this project.

The Mid-career Development Programme. In 2010 the Faculty launched a mid-career fellowship programme with the support of the Hasso Plattner Foundation. The FHS is seeking additional funds to enhance and expand this programme. Posts are awarded to outstanding emerging young basic or clinical scientists, to enable them to develop and take their research to a new and higher level. This initiative aims to produce researchers who are able to secure major international funding and grants from prestigious agencies, such as the National Institutes of Health, to enable them to pursue their own projects and careers. Over a 5-year period, 10 awards will be made. Awardees are expected to develop and sustain national and international research partnerships, collaborations and network ties, attain NRF ratings, be capable of undertaking interactive and multidisciplinary research and provide mentorship for early-career investigators.

The MMed Programme. The Master of Medicine programme deserves special mention. Since January 2012, all registrars undertaking specialty training are required by the HPCSA to complete an MMed thesis, based upon a research project, to register as specialists. The FHS undertakes to support individual projects and the C-CRITT will be important in this regard.

\section{Retaining and rewarding research excellence}

The Faculty has a complement of highly qualified and productive academics as measured by research outputs. Nevertheless it is difficult to attract and retain senior staff when competing with institutions in developed countries, which offer higher salaries and better conditions of service. Improving the research environment, offering more funding (from Faculty research spend), offering more student scholarships at doctoral and postdoctoral level, ensuring that students and staff have access to world-class facilities, and relieving productive researchers of heavy administrative responsibilities are key to retaining such senior personnel. We must also create more mid-career/development posts and further incentivise research in innovative ways to retain up-and-coming mid-career scientists. 


\section{Continuing support for the high quality lead projects}

Unsurprisingly, the focus of research over the last two decades has largely been dictated and driven by the human immunodeficiency virus (HIV) and tuberculosis. Groups have emerged under the auspices of the Institute of Infectious Disease and Molecular Medicine, which undertake excellent research in these fields. While this thrust is unlikely to change, research into conditions such as cancers, noncommunicable diseases, neurological and psychiatric conditions will be prioritised over the next 5 years, in line with national and international trends and initiatives (see below).

\section{Priorities}

Priority setting is often complex, difficult, contentious and controversial. There must be alignment between the FHS strategy and the strategies of other national agencies, such as the National Health Research Committee, the Department of Science and Technology (DST) and the Medical Research Council. The priorities for the FHS should also take cognisance of key policy mandates of the government such as the 'National Strategic Plan for HIV/AIDS, STIs and TB, 2011 - 2016' and the DST's 'Ten-Year Innovation Plan'.

Health research priorities should be determined by the national and global burden of disease. While low- and middle-income countries bear a disproportionate burden of communicable diseases, non-communicable conditions, such as neuropsychiatric disorders, cancers and cardiovascular diseases, are increasingly onerous in middle-income countries such as SA. The United Nations has endorsed the Millennium Development Goals and identified 8 goals to achieve by 2015. Three of these are specific to healthcare: (i) reduce child mortality, (ii) improve maternal health; and (iii) combat HIV/AIDS, malaria and other major diseases. The FHS must recognise these priorities and tailor research efforts accordingly.

Promoting research capacity in key underdeveloped areas The Faculty already has strong, well-developed and well-co-ordinated research programmes in areas such as infectious diseases, sports science and public health. There are also excellent research groups in disciplines such as cardiology, immunology, genetics and biochemistry. The future focus must be research, highlighted by groups such as the NIH from whom greater funding is being made available, in thematic areas such as cancer, non-communicable diseases and the neurosciences which constitute major burdens of disease in SA. Several initiatives have been taken, e.g. the Cancer Research Initiative and the Chronic Diseases Initiative. Biostatistics, bioinformatics, genomics and structural biology, which represent key underpinning disciplines, are being developed. Against the background of all this activity, core strengths must be preserved; any major investments in new areas must be strategic and built on evidence of competitive advantage to UCT.

\section{Translation}

To improve the health and well-being of our population, scientific discoveries must be translated into practical applications capable of innovative and cost-effective implementation.

Whatever research we plan to conduct should have a translational component and bridge either basic and clinical science or clinical and public health science. This bench-to-bedside approach to translational research permits basic scientists to provide clinicians with new tools for use with their patients and for assessing their impact. Similarly, clinical researchers make novel observations about the nature and progression of disease which stimulate basic science investigation. The planned C-CRITT project will be central to supporting this specific strategy.

We hope that this translational strategy will encourage and enable meaningful collaboration between researchers within the FHS and decision and policy makers who will be able to use research results to address health challenges.

\section{Promoting collaboration and partnerships}

This relates to: (i) promoting internal partnerships within the Faculty and the need for researchers to avoid conducting (and the Faculty to avoid supporting) 'silo research'; (ii) promoting internal partnerships within the University between FHS-based researchers and their colleagues located in other faculties; (iii) partnering with groups external to the University, in other universities, science councils and research institutes, nationally and internationally, within and external to Africa. We will seek to promote collaborative research activities which are inter-, cross- and multidisciplinary within the University.

\section{Conclusion}

We have provided an overview of the current status of research and reveal the Faculty's vision of the next 100 years of research. The quality of any institution's health science research is whether its results meaningfully and positively impact on the lives of the population it serves. We believe that our Faculty has made, continues to make, and will make future significant contributions.

Acknowledgements. We thank Yolande Harley, Valerie Mizrahi, Karen Barnes and Carlette Hlungwani for providing input and their constructive comments.

\footnotetext{
1. Hansen J. John Fleming Brock. J Nutr 1987;117:1815-1819.

2. Brock JF. Clinical research. S Afr Med J 1939;13:291-295.

3. Times Higher Education - 2010 world university rankings. http://www.timeshighereducation.co.uk/ . Times Higher Education - 2010 world university rankings. http://www.timesh
world-university-rankings/2011-2012/africa.html (accessed 10 January 2012).

4. University of Cape Town. Research Report 2010. http://www.research2010.co.za/nodepage.php?nid=963 4. University of Cape Town. Reser
(accessed 10 January 2012).

5. University of Cape Town. Vice-Chancellor's Report 2010. http://www.uct.ac.za/downloads/uct.ac.za/ about/management/vcreport2010.pdf (accessed 10 January 2012).
}

Accepted 2 February 2012. 